\title{
Hilvanando redes entre familias e iglesias evangélicas en contextos de pobreza en Córdoba, Argentina
}

\author{
Julieta Capdevielle*
}

\section{Resumen}

El presente artículo propone un estudio de caso comparado que analiza las prácticas institucionales desplegadas por dos iglesias protestantes en la localidad cordobesa de Malvinas Argentinas. El propósito principal de nuestro trabajo es explicar y comprender las estrategias desplegadas por estas dos instituciones religiosas centrando el análisis en los vínculos que entretejen la vida de las familias a las de las iglesias. El análisis parte del hecho que, en la actualidad, Argentina presenta un incremento de las iglesias protestantes y de sus fieles, mientras paralelamente se produce una disminución de la población católica. Esto se debe a que los grupos evangélicos se multiplican, en parte, por su capacidad de brindar soluciones, a través de sus discursos y prácticas, a diversas necesidades simbólicas y materiales inmediatas de un colectivo amplio de creyentes. Se desprende que la construcción de redes sociales constituye uno de los mecanismos que ponen en juego tanto las instituciones como las familias involucradas para asegurar su sostenimiento cotidiano y generacional.

Palabras Claves: redes sociales, familias, iglesias evangélicas, pobreza.

Tacking networks between families and evangelics churches in contexts of poverty in Córdoba, Argentina.

\section{Summary}

This paper, as part of my $\mathrm{PhD}$ thesis, proposes a comparative case study that analyzes institutional practices deployed by two Protestant churches in the province of Cordoba in the town of Malvinas Argentinas. The main purpose of our work is to explain and understand the strategies used by these two religious institutions focusing the analysis on the links that weave the lives of the families of churches. The analysis starts with the fact that Argentina shows currently an increase of Protestant churches and their faithful, while there is a parallel decline in Catholic population. Evangelical groups are multiplied, in part, by its ability to provide solutions through their discourses and practices, various symbolic and material needs immediate a broad group of believers. We understand that building social networks is one of the mechanisms that come into play both the institutions and the families involved to ensure daily and generational sustenance.

Keywords: social networks, families, protestant churches, poverty.

\section{Introducción}

Numerosas investigaciones que abordaron casos empíricos en el ámbito de las ciencias sociales (Lomnitz, 1978; Bartolomé, 1985; Ramos, 1981; Torrado, 1982; Hintze, 2004; Gutiérrez, 2004; entre otros) confirman la importancia del capital social como recurso alternativo decisivo que las familias pobres emplean para hacer frente a las necesidades cotidianas y de reproducción

\footnotetext{
Becaria del Consejo Nacional de Investigaciones Científicas y Técnicas (CONICET) en el Centro de Investigaciones de la Facultad de Filosofía y Humanidades. Pabellón Agustín Tosco. Ciudad Universitaria, Córdoba, Argentina. E-mail: julietacapdevielle@gmail.com
} 
social. Las redes sociales proveen cierta estabilidad frente a las inseguridades del mercado laboral y al escaso volumen de capital cultural que cuentan dichas familias.

Partiendo de estas investigaciones, el propósito principal de este trabajo es explicar y comprender las prácticas desplegadas por dos iglesias protestantes (la iglesia pentecostal "Jesús es la Luz del Mundo" y la Iglesia "Un lugar para el encuentro con Dios" de la rama de los Hermanos Libres). Centramos el análisis en las redes sociales ${ }^{1}$ que se establecen entre estas dos instituciones y sus miembros.

A lo largo del trabajo sostenemos un doble supuesto: por un lado, consideramos que, dentro del conjunto de prácticas institucionales de las iglesias protestantes, la construcción de redes sociales tiene un lugar destacado. Las redes sociales entrelazan la vida de las familias a la de las iglesias, en donde la pertenencia al espacio religioso necesariamente implica reciprocidad para los agentes involucrados. Y, en segundo lugar, consideramos que en el sistema de las estrategias de reproducción social ${ }^{2}$ las familias pobres generan prácticas que toman como apuesta principal su disponibilidad de capital social, movilizado en intercambios a través de diferentes tipos de redes, entre ellas las religiosas.

Los efectos de la conversión religiosa en la situación económica y social de los sectores pobres ha sido debatida por un extenso número de estudios (entre otros, Roberts 1968; Mariz, 1990, 1994; Covarrubias-Cuéllar 1998, 2010). Estos autores, en contextos diferentes como el brasileño, chileno, guatemalteco y mexicano, han abordaron la relación entre situaciones económicas de pobreza y religiones protestantes.

Reconociendo los aportes de estas investigaciones, buscamos -a través de una aproximación de corte cualitativo pero en relación con las transformaciones macrosocialesexplicar y comprender las estrategias desplegadas por dos iglesias protestantes, centrando el análisis en los vínculos que se establecen entre estas dos instituciones y sus miembros. Con ello, buscamos identificar los diferentes tipos de redes sociales que construyen las iglesias conjuntamente con las familias pobres, en el marco de sus estrategias de reproducción social, apelando a su capital social en sus formas colectiva, doméstica o individual.

En función de este objetivo, analizamos el repertorio de prácticas desplegadas por las dos instituciones religiosas. Desde nuestra perspectiva se vuelve imprescindible analizar las lógicas institucionales, las prácticas y representaciones que estos grupos ponen en juego; como también las identidades ${ }^{3}$ que se construyen en estos espacios. Finalmente, concluimos con una reflexión

\footnotetext{
${ }^{1}$ La conceptualización de red y capital social se inspira sobre todo en Pierre Bourdieu, quien asocia ambas nociones. El autor entiende al capital social como "conjunto de recursos actuales o potenciales que están ligados a la posesión de una red duradera de relaciones más o menos institucionalizadas de interconocimiento y de inter-reconocimiento; o, en otros términos, a la pertenencia a un grupo, como conjunto de agentes que no están solamente dotados de propiedades comunes (susceptibles de ser percibidas por el observador, por los otros o por ellos mismos) sino que están también unidos por lazos permanentes y útiles" (Bourdieu, 1980: 2; énfasis original).

${ }^{2}$ Desde la perspectiva teórica de Pierre Bourdieu las estrategias de reproducción social se definen como "el conjunto de prácticas fenomenalmente muy diferentes, por medio de las cuales los individuos y las familias tienden, de manera consciente o inconsciente, a conservar o a aumentar su patrimonio, y correlativamente a mantener o mejorar su posición en la estructura de las relaciones de clase" (Bourdieu, 2000: 122). Si bien el concepto fue esbozado, en principio, para referirse a las estrategias desplegadas por los grupos familiares, nos parece que es extensible a instituciones, en este caso, religiosas.

${ }^{3}$ Los agentes producen y sostienen su identidad a partir de elementos objetivos de la estructura social y la percepción subjetiva de sus portadores, relación que exige un mantenimiento y una adecuación constante en el programa de vida, de tal manera que se genere en el sujeto la certeza de que vive "correctamente", otorgándole un sentimiento de pertenencia y seguridad (Reguillo, 1996). Desde esta concepción se entiende a la identidad como una construcción que se elabora en relación con otros, como una manifestación relacional. Esta noción permite superar la dicotomía
} 
sobre las redes de intercambio religiosas y su incidencia o no en la superación de las condiciones de pobreza en las que se encuentran las familias involucradas.

Cabe agregar que, desde nuestra perspectiva de análisis, para comprender las prácticas sociales es necesario conocer tanto las condiciones materiales de existencia -que establecen el grado de acceso a determinados espacios, bienes, etc.-, como las representaciones que los agentes ponen en juego con el fin de comprender cómo definen sus prácticas cotidianas, su propia realidad y los constructos que organizan su mundo. De este modo, la caracterización de las prácticas sociales de los agentes al interior del espacio religioso se ha realizado a partir del trabajo de indagación sobre las estrategias y los capitales puestos en juego y, asimismo, desde las formas en que esos agentes estructuran sus decisiones (de acuerdo con sus condiciones materiales, sus trayectorias y el cúmulo de intercambios).

Los avances que presentamos en este trabajo son parte de una investigación más amplia desarrollada en el marco de nuestra tesis de doctorado. Se trata de un estudio de caso ${ }^{4}$ comparado en la perspectiva etnográfica (Neiman y Quarenta 2007). Ésta tiene la particularidad de permitir articular lo micro y lo macro, ya que en el caso "se manifiesta de manera particularizada y singular la acción de dimensiones y mecanismos sociales de carácter general" (Jelin et al. 1999: 133). El trabajo de campo implicó el uso de diferentes instrumentos: desde encuestas a través de historias de vida, cuestionarios, entrevistas en profundidad (a informantes claves, a miembros activos de las iglesias, a otros agentes involucrados en los procesos), observación y asistencia a las reuniones generales, reuniones de mujeres, ministerios y células.

Los desarrollos que siguen no suponen que pretendamos extender las inferencias construidas a partir de este estudio de caso a otros. Por el contrario, privilegiamos a lo largo de la investigación la efectividad de la particularización sobre la validez de la generalización (Neiman y Quaranta 2007). De este modo, nos preocupó más que la representatividad del caso analizado, la profundización y el conocimiento global del mismo. El trabajo de investigación supuso, en este sentido, una construcción marcada por la complejidad: nos propusimos comprender la singularidad de las instituciones religiosas -con sus estructuras de poder y sus mecanismos de dominación- como así también dar cuenta de las respuestas a ciertas necesidades, simbólicas y materiales, que los fieles encuentran en estos espacios.

Identificamos, así, la tensión entre dos dimensiones que atraviesan las lógicas de funcionamiento de las instituciones religiosas. Una de ellas nos habilitó el abordaje de los espacios religiosos como ámbitos en donde los fieles encuentran respuestas y soluciones a sus necesidades cotidianas y construyen su identidad. La segunda dimensión nos permitió analizar a las instituciones religiosas como espacios de dominación simbólica atravesados y articulados por

subjetivismo/objetivismo, ya que expresa la resultante de las diversas interacciones entre el individuo y su entorno social. La identidad permite que el individuo se ubique en el sistema social y que él mismo sea ubicado socialmente: en una clase social, género, grupo etario, etc. Es decir, la identidad es esencialmente pertenencia. El pertenecer a "algo" implica compartir un lenguaje, un estilo, ciertas rutinas. De este modo, las identidades colectivas pueden ser leídas como "redes de comunicación desde donde se procesa y se difunde el mundo social de acuerdo con un referente común -objeto o fin- sirviéndose de unos códigos específicos -lenguajes, señales, símbolos- que el grupo comparte" (Reguillo 1996: 56).

4 Los estudios de caso se definen por abordar un determinado fenómeno ubicado en el tiempo y espacio. El o los casos de un estudio pueden estar constituidos por un hecho, un grupo, una relación, una institución, una organización, un proceso social o una situación de escenario específico, construido a partir de un determinado y siempre subjetivo y parcial recorte empírico y conceptual de la realidad social, que conforma un tema y/o problema de investigación. Los estudios de casos tienden a focalizar, dadas sus características, en un número limitado de hechos y situaciones para poder abordarlos con la profundidad requerida para su comprensión holística y contextual (Neiman y Quaranta 2007). 
relaciones de poder. A su vez, insertamos nuestro estudio de caso en el marco de realidades mayores en las que se inscriben las prácticas institucionales y de las familias miembros, atendiendo a las regularidades pero también al cambio, considerando al sujeto pero también la estructura e identificando condiciones objetivas pero también simbólicas.

A lo largo del trabajo de campo, que se extendió desde julio de 2008 hasta abril de 2011, al interior de la metodología cualitativa, recuperamos esencialmente las técnicas de entrevistas en profundidad (a informantes claves, a miembros activos de las iglesias, a otros agentes involucrados en los procesos), observación y asistencia a las reuniones generales, reuniones de mujeres, ministerios y células. Por lo tanto, nuestra estrategia apuntó a complementar y fortalecer los datos estadísticos ${ }^{5}$ (de encuestas y censos) con etnografías en la vida cotidiana del templo, incluyendo la asistencia a reuniones generales, reuniones de mujeres, reuniones de matrimonios, escuela dominical, café Show, ensayos de banderas, panderos y manto. En lo que refiere a la delimitación de los casos entrevistados, la opción por un muestreo selectivo, lejos de aspirar a una representación estadística, se orientó a la búsqueda de actores que acuerden con ciertos rasgos considerados relevantes desde nuestra perspectiva teórica-conceptual, a los fines de comprender cierto fenómeno a partir de una pluralidad de voces (Mallimaci y Belivéau, 2006). Así, dentro de los procedimientos de muestreo no probabilísticos, utilizamos, en algunas oportunidades, la táctica de la "bola de nieve" 6 para acceder a nuevos entrevistados. Por otro lado, cabe agregar que no todos los encuentros y charlas en profundidad fueron grabados. En muchas oportunidades, preferimos registrar estas instancias en el cuaderno de campo porque notamos que la presencia del grabador interrumpía la fluidez del diálogo y la situación informal que se estaba desarrollando. De igual modo, estos encuentros y conversaciones informales se constituyeron en una importante fuente de información que nos permitió acceder a las percepciones y a la cotidianeidad de los sujetos. En estas ocasiones, el principal método de registro fue la observación participante centrada fundamentalmente en la mirada y la inmersión en las actividades, desde un criterio de conocimiento que privilegia la introyección de la cultura estudiada por sobre la distancia objetiva con pretensiones de neutralidad (Lapantine, 1996 en Algranti, 2009a).

\section{La expansión de las iglesias pentecostales: De a poco, mucho}

En los barrios más pobres de numerosas ciudades argentinas se destaca la presencia creciente de un tipo especial de iglesias pentecostales. Se trata de pequeños locales que cuentan entre su feligresía un gran porcentaje de vecinos y familiares. "Cuanto más pobre es el barrio, más abundan estas pequeñas iglesias que aunque cada una de ella congrega unas pocas decenas de fieles, suman decenas de iglesias en cada barrio" (Semán, 2010:17).

Surgido en Estados Unidos a comienzos de siglo, el pentecostalismo puede ser definido como "un movimiento religioso que postula la "actualidad de los dones del 'Espíritu Santo', la oportunidad de un encuentro personal con la divinidad y, más laxamente, la afirmación de la posibilidad de intervenciones divinas en la vida cotidiana de los creyentes" (Semán 2006: 199). Durante la década del cincuenta, su presencia se consolida con iglesias y pastores locales, pero su gran expansión se produjo hacia fines de los años setenta.

\footnotetext{
5 Una de las principales fuentes utilizadas es la Primera Encuesta sobre Creencias y Actitudes Religiosas en Argentina -CEIL PIETTE CONICET- en http://www.ceil-piette.gov.ar

6 Este procedimiento consiste en escoger las unidades muestrales a partir de las referencias que van aportando los sujetos ya entrevistados.
} 
Múltiples son las razones que dan cuenta de dicho crecimiento. Fue este movimiento religioso -entre otros- quien pudo brindar respuesta, a través de sus discursos y prácticas, a ciertas necesidades simbólicas y materiales inmediatas de un colectivo amplio de creyentes. Así, el postulado de la "actualidad de los dones del Espíritu Santo" habilita la posibilidad concreta y cotidiana de que lo divino intervenga en la vida de cada creyente. El contacto con la divinidad podía manifestarse de múltiples formas: a través de visiones, de la glosalia (hablar en lenguas desconocidas), en la posibilidad de sanación de enfermedades, entre otras. "Se trata, en fin, de un cristianismo de milagros muy cercanos y disponibles generosamente para todos los que se atrevieran a buscarlo" (Adamovsky, 2012: 400).

Como plantea Pablo Semán (2000) los grupos pentecostales consiguieron "revalorizar creencias tradicionales que ni la Iglesia Católica ni las instituciones modernas tienen en cuenta y, al mismo tiempo, las adaptan a las problemáticas específicas de los sectores populares urbanos" (2002: 162). De este modo, "los grupos pentecostales abren paso a la formación de puentes de continuidad -asociativos y sustitutivos- con relación a algunos núcleos activos de la religiosidad practicada por diferentes grupos sociales" (Berges 2008: 205). Además, el pentecostalismo tuvo éxito con las clases populares por su cercanía social. Los grupos pentecostales ofrecen la posibilidad de multiplicar las jerarquías religiosas en torno a individuos dotados de carisma, que en muchas ocasiones carecen de un elevado nivel de escolaridad formal. De este modo, cualquier persona puede aprender el oficio de pastor alcanzaba con observar a otros líderes o leer la bibliografía que explicaba los ritos y doctrinas de manera más simple. A su vez, tener antecedentes socialmente reprochables -haber sido ladrón, adicto, curandero o estar divorciadono sólo no era causa excluyente, sino que podía funcionar como prueba de la intervención de Dios en sus vidas, lo que les agregaba legitimidad para llevar el mensaje de salvación (Adamovsky, 2012).

Por último, también es posible mencionar la conversión al pentecostalismo como una de las tantas estrategias desplegadas (movilizaciones gremiales, movimientos vecinales, creaciones de comedores populares, etc.) por los sectores populares frente a un modelo social caracterizado por el aumento del desempleo y de los índices de pobreza e indigencia (Minujin et al. 1993; Beccaria y López 1996; Grassi 1997). En el caso argentino, dicho modelo social tuvo como hito fundacional el golpe de Estado del 24 de marzo de 1976. ${ }^{7}$ A partir de ese momento, se implementaron políticas en las que predominó la inversión financiero-especulativa en detrimento de la inversión productiva, la que cayó abruptamente y produjo, por el ingreso masivo de importaciones, la destrucción del aparato productivo nacional, es decir, el fortalecimiento de los oligopolios, la concentración económica y la especulación. Estas medidas estuvieron acompañadas de un fuerte ajuste fiscal basado en una reducción drástica del gasto público. Es así que la proliferación de estos grupos religiosos -como plantea Berges (2008)- desempeñó un papel destacado la búsqueda de recursos compensatorios. Con frecuencia, los creyentes resaltan las perspectivas de salvación y protección producidas por el encuentro con Dios. Utilizan términos que expresan transformaciones operadas en sus vidas y sentimientos de seguridad. De este modo, un sector de la población encuentra en lo religioso una manera de sentirse seguro, protegido frente a un escenario social marcado por la incertidumbre.

\footnotetext{
${ }^{7}$ Recordemos que en 1974, en la Argentina, "la distribución de la riqueza era similar a la de muchos países desarrollados: los ingresos del 10\% más rico eran 12,7 veces mayor que el del 10\% más pobre” (Svampa 2005: 23).
} 


\section{Vida cotidiana y religiosa de una localidad cordobesa}

La localidad de Malvinas Argentinas se encuentra ubicada a 12 kilómetros de la capital de Córdoba. Esta localidad está atravesada por dos rutas: la Ruta 19 y la ruta provincial A 188. Dichas arterias dividen en tres secciones a una localidad sin dinámica económica propia y altamente dependiente de la ciudad de Córdoba. Malvinas Argentinas se ha constituido en un centro receptor de población de menores ingresos, fundamentalmente provenientes de la ciudad de Córdoba, cobrando así características de "ciudad dormitorio de pobres" (Tecco y Bressan, 2000-2003). Esto se debe principalmente a su cercanía a la capital (centro de abastecimiento y de trabajo) y por el costo accesible del suelo y de la vivienda.

Las actividades que desempeñan los hombres son de cuentrapropismo, llevadas a cabo de manera irregular y precaria. Las mujeres, por su parte, se dedican a las actividades domésticas y al cuidado de los niños y la minoría que trabaja lo hace como empleadas domésticas. Según los datos del Programa Materno Infantil de la Nación (PROMIN), la población ocupada se distribuye entre las siguientes categorías: obreros o empleados $(35 \%)$, trabajadores por cuenta propia o patrones $(16 \%)$ y trabajadores precarios (50\%). Como se observa, la mayoría de los empleos de los habitantes de la localidad se caracterizan por su informalidad ${ }^{8}$ y precariedad. Cabe agregar que el nivel de escolarización predominante de los habitantes de esta localidad llega hasta el primario y unos pocos han terminado la secundaria.

No obstante, Malvinas Argentinas tiene una activa vida religiosa. Una multiplicidad de grupos integra el mapa religioso local, entre los que se destaca la presencia de Católicos, Adventistas del Séptimo Día, Los Santos de los últimos Días -conocidos como mormones-, Hermanos Libres y pentecostales.

Según los relevamientos de la investigación, en la tercera sección de Malvinas Argentinas la mayoría de los hogares (89\%) manifestó profesar alguna religión y, entre estos, el $82 \%$ se definió católico, pero con poca participación en ceremonias de liturgia y sacramentos. Entre quienes manifestaron profesar otros cultos (evangélicos, testigos de Jehová y Mormones), se evidencia un mayor grado de compromiso, traducido en su participación directa en las prácticas propuestas (llegando incluso a trasladarse periódicamente a Córdoba para las mismas, especialmente quien se congrega en MEDDEA o iglesias evangélicas).

La iglesia católica de la localidad cuenta con dos capillas, "San Cayetano" y "Santa Rita", y con varios colegios primarios donde se lleva a cabo actividades de catequesis y guarderías sostenidas por CARITAS y la Municipalidad. El catolicismo aparece controlado por las familias que ocupan las posiciones dominantes dentro de la localidad, sin embargo, no posee una feligresía estable, mientras que las iglesias pentecostales son la opción de las familias más pobres. Las iglesias pentecostales están integradas por familias que, en promedio, son más pobres que las que componen el Catolicismo y la Iglesia de los Hermanos Libres.

\footnotetext{
${ }^{8}$ La informalidad laboral se refiere principalmente a las características precarias de la actividad, al escaso capital con el que se desarrolla, al bajo nivel de productividad, al reclutamiento laboral basado en redes de proximidad y a la ausencia del Estado en la protección del trabajo (Chávez Molina y Raffo, 2005). La dualidad formalidadinformalidad es heredada, al menos en América Latina, de los debates sobre el subdesarrollo y la marginalidad, lo cual introduce el problema de la heterogeneidad estructural a nivel del sistema productivo y el mercado de trabajo. Es muy posible que estas categorías resulten en realidad insuficientes para captar en toda su complejidad las nuevas condiciones de precariedad y fragmentación social que han tenido lugar durante el último cuarto de siglo, aunque por su parte parecen tener la virtud de reinstalar el problema del crecimiento desigual y la inequidad de oportunidades en el contexto de las crisis y reformas estructurales que tienen lugar en las sociedades nacionales bajo la economía globalizada (Salvia, 2002).
} 


\subsection{La llegada a la localidad...}

Un anexo de la congregación pentecostal "Jesús es la Luz del Mundo" se instaló en la localidad de Malvinas Argentinas hace veinte años atrás, como resultado de un proceso de apadrinamiento de la iglesia central, ubicada en la ciudad de Córdoba. La instalación de la congregación se vio facilitado por la actualización y puesta en funcionamiento de redes sociales en este caso familiares- preexistentes a la congregación. De este modo, la institución da sus primeros pasos en la localidad a través de la vinculación familiar existente entre mujeres.

-En esa época era todo campo esto, no había calles sólo senderos que unían una casita con la otra. Íbamos con mi consuegra a visitar a la familia de Estela. De a poco comenzamos a armar las reuniones de oración en la casa de Estela, ella invitaba a sus vecinas y nosotras veníamos a veces con el pastor de la iglesia central. Durante seis meses fuimos a la casa de Estela y hacíamos la reunión ahí..." (Marta, 73 años, jubilada nacional, Diácona de la iglesia).

En una primera instancia, son los mismos miembros de la iglesia quienes donan un espacio en sus casas para llevar adelante reuniones de oración. Cuando la casa de oración ya está consolidada como lugar de concurrencia de nuevos creyentes, se intenta conseguir algún terreno donde edificar una nueva sede.

-Ahora tenemos, además, una en la Villa, en donde el gobierno hizo casas para la gente de la Villa, y pasando ese lugar alquilamos una iglesia metodista que la habían cerrado y alquilamos ahí otra. O sea que tenemos esta iglesia y dos anexos más (Raúl, 55 años, ex portero de un colegio, pastor de la iglesia).

El modelo de gestión corporativista, multiplicado en cientos de pequeñas iglesias autónomas (Semán 2010) dirigidas por pastores perteneciente a los sectores populares posibilitó la instalación de este anexo en la localidad.

-Es como si alguien viene y dice: yo tuve el llamado de servir y abrir una iglesia en este lugar, bueno, el fundador de esta iglesia, mientras se fue formando, así como acá se fueron formando obreros, se fueron formando gente, esa gente sintió el llamado para otros barrios, otras provincias, otros sectores de Córdoba (Nadia, 31 años, ama de casa, hija del pastor, líder del Ministerio de Jóvenes)

-Sería como la Iglesia central, la Iglesia madre la que envió. Envió acá al pastor, envió a Carlos Paz, envió, ¿entendés? De ahí nacieron todos... (Juan, 29 años, empleado de una fábrica metalúrgica, líder del Ministerio de Jóvenes, esposo de Nadia).

-Se van extendiendo como en una red ¿entendés? La madre está en San Vicente pero a la vez tenemos un brazo en Floresta, un brazo allá en Simbolar, en Carlos Paz, en Calera, se van abriendo esos brazos de esa misma (Nadia, 31 años, ama de casa, hija del pastor, líder del Ministerio de Jóvenes).

La organización descentralizada que estas iglesias ponen en marcha permite a sus miembros llegar a ocupar posiciones de liderazgo en las distintas actividades de la congregación (líderes de mujeres, líderes de adolescentes, etc.). En la iglesia "Jesús es la Luz del Mundo" un portero de escuela y su señora, ama de casa, se convierten en los líderes a mediados de los años noventa. 
-En cambio yo, sí era muy muy católica y no quería saber nada de cambiarme, pero un día mi hermana me invitó y terminé aceptando, yo me convertí con un nene de 6 años que me predicó. Sentí como si me hubieran sacado un velo de encima, como si empezara a ver. Desde ese día hace como 40 años. Y ya no me aparté más...en 1994 ungieron de pastor a Raúl y a nosotras de diáconas (Marta, 73 años, jubilada nacional, Diácona de la iglesia).

Así, el modelo de gestión flexible que los grupos pentecostales utilizan permite a los fieles un crecimiento al interior de las estructuras de las iglesias. ${ }^{9}$ De este modo, las iglesias se constituyen en un espacio de pertenencia e identidad donde los miembros pueden, con el tiempo, ocupar posiciones de liderazgo. El ámbito religioso se constituye así para los sectores pobres en una posibilidad certera de crecimiento frente a un escenario social marcado por la ruptura de los vectores tradicionales de ascenso social.

Los puentes de continuidad asociativos y sustitutivos con relación a algunos núcleos activos de la religiosidad practicada por diferentes grupos sociales es otro factor clave. La impostación de manos como herramienta de sanidad; el uso del cuerpo y la música son elementos que hablan de estos lazos comunicantes entre religión popular y grupos pentecostales. ${ }^{10}$

A su vez, las prácticas al interior del espacio religioso analizado no están mediadas principalmente por la lecto-escritura sino que, en su lugar, el uso del cuerpo, lo gestual, el canto, la música, y la comunicación verbal ocupan un lugar destacado. Así, cada reunión general da inicio con un conjunto de alabanzas por medio de la música y la danza. La orquesta de la iglesia ubicada en el escenario se encarga de que el sonido llegue a cada rincón del amplio salón. Un grupo de mujeres y hombres ubicado debajo del escenario acompañan los sonidos por medio del uso del cuerpo e instrumentos (panderetas, mantos, banderas y estandartes) que rotan de reunión a reunión.

-Bueno, cuando yo era chica, hace un montón, como 30 años atrás, se usaba antes la pandereta (...) Bueno, y después apareció, vinieron de allá de México con las banderas, ya vinieron con manto, con los distintos ministerios, con los estandartes. Se fueron levantando distintos ministerios, en ese sentido. Nosotros damos talleres los sábados (...) Las mismas que saben les enseñan a las que no saben. Entonces se van integrando al grupo y lo mismo pasa con las banderas y lo mismo con los mantos. En el área espiritual, se hace batalla en el área espiritual. $\mathrm{O}$ sea cada patrón porque todo se rige por patrones, ¿entendes? Por ejemplo no es que movemos porque se nos ocurre sino que cada toque es un patrón y cada patrón tiene un versículo bíblico y tiene un nombre, o sea está sacado de la Biblia, cada patrón, va acompañado de un versículo bíblico, cada toque significa algo, como describiendo un versículo bíblico a través del movimiento (Nadia, 31 años, ama de casa, hija del pastor, líder del ministerio de jóvenes).

\footnotetext{
${ }^{9}$ Las posiciones dominantes dentro de la congregación analizada son ocupadas, en primer lugar, por los pastores y, en segundo lugar, por los diáconos, mientras que los obreros (líderes encargados de los distintos grupos: adolescentes, jóvenes, entre otros) y músicos se encuentran por debajo de ellos. En la base de la estructura se encuentran el resto de la congregación.

${ }^{10}$ Según la Encuesta Sobre Creencias y Actitudes Religiosas en la Argentina. el 76\% de la población se define como católico, mientras que un 9\% se declara Evangélico y, dentro de ese 9\%, un 7, 9\% pertenece a los grupos pentecostales (CEIL PIETTE, CONICET en <http://www.ceil-piette.gov.ar/areasinv/religion/relproy/1encrel.pdf>).
} 
Es así como las formas de alabanzas en particular y las prácticas en general que tienen lugar en las iglesias pentecostales se amoldan y complementan con las de los sectores populares, construyendo lazos de pertenencia y reciprocidad.

\subsubsection{Capitales entrelazados: familias e iglesias pentecostales}

Las redes de intercambio constituyen uno de los elementos fundamentales, que facilitan el sostenimiento y la reproducción de la iglesia. Desde nuestra perspectiva, la construcción de redes forma parte del conjunto de prácticas que las familias y las iglesias ponen en marcha para vivir y reproducirse socialmente. Las redes sociales garantizan a los agentes la pertenencia al espacio religioso convirtiéndolos en miembros activos y, al mismo tiempo, los provee de una diversidad de recursos. Los fieles participan de las redes de múltiples maneras, involucrándose en procesos que implican intercambio, reconocimiento mutuo y reconocimiento de la pertenencia a un grupo.

- ¿Y hace cuántos años que es miembro de la iglesia?

- "No me acuerdo el año... pero hace como tres años. A mí me gusta, yo aprendo con ellas, a lo mejor yo conozco la necesidad de ellas, las conozco más como son, o ellas me conocen a mí, saben la necesidad mía. Y esas cosas... estamos en comunión y también para orar. Siempre estamos haciendo algo..." (Cristina, 62 años, jubilada nacional, Obrera de la iglesia).

De esta manera, la incorporación al pentecostalismo crea, para los agentes, un conjunto de nuevas relaciones sociales que se agregan, sin sustituirlas ni obstaculizarlas, a las existentes. Viejas y nuevas redes se entrelazan y complementan.

-"Hay que visitar a las hermanas, aquellas que se estén preparando, que estén orando, tienen que ir a ver a las hermanas, hay hermanas que tienen necesidades, hay que hablar con el resto de las mujeres y hacer las visitas" (Marta, 73 años, jubilada nacional, Diácona de la iglesia).

-"Bueno, el estar unidas, el ayudarnos, el escucharnos en las necesidades que tengan algunas, si necesitan oración, si necesitan lo monetario, y bueno, uno en seguida comunica al pastor (...)" (Ana María, 52 años, ama de casa, Diácona de la iglesia, esposa del pastor).

A través de estas tramas, las familias que participan en las actividades de las iglesias dan respuestas a múltiples necesidades y problemas: el capital social colectivo es reconvertido entonces -en múltiples oportunidades- en forma de apoyo emocional, ayuda y servicios. Las redes son utilizadas, por ejemplo, en la gestión de diversos trámites en entidades públicas como hospitales, dispensarios, la Municipalidad y en el cuidado de niños y ancianos.

- ¿Y los sábados le dan la copa de leche a los chicos?

-Sí, le dan té con facturas, con criollos, sí se trabaja y se está trabajando duro (Marta, 73 años, jubilada nacional, Diácona de la iglesia).

-"Yo tuve que ir al médico esta mañana a retirar unos análisis. Por suerte, la doctora me atendió temprano y a las 12 ya estaba en la iglesia. Fui con la hermana Mónica, ella siempre me acompaña cuando tengo que ir a médico (...) Mañana tenemos que volver para que me hagan otros análisis..." (Nota de campo, charla con Valentina, Obrera de la iglesia). 
Para gran parte de los sectores populares, "Los recursos religiosos no son un escapismo, una reflexión espiritual posterior a las necesidades materiales, sino una parte de su arsenal cotidiano a la hora de definir los problemas y las soluciones" (Semán, 2000: 155). Sin embargo, otra dimensión de este capital social lleva a captar la dinámica interna de las congregaciones, como espacio de juego, de apuestas y de luchas. Al interior de la institución religiosa los agentes están dotados de distintas especies de capital y han incorporado distintas trayectorias, lo que ubica a los agentes en posiciones diferenciales, que conceden sólo a algunos el poder de la enunciación, de la toma de decisiones, la capacidad de gestión y el manejo de determinados recursos: es el pastor, por ocupar la posición dominante, el que canaliza y gestiona la ayuda (capital económico bajo diversas formas) entre los integrantes. Así, en dicha estructura jerárquica, cobra centralidad y legitimidad la posición del pastor, fenómeno al que nos referimos en trabajos anteriores con la noción de pastorcéntrico ${ }^{11}$ (Aviles et al., 2012).

"El pastor dice, bueno, hermanos, hay un hermano que tiene necesidad y queremos que todos lo ayudemos, así que vamos a hacer un bolsón a ver hermanos qué pueden poner para el día miércoles, todos vengan con algo para hacer un bolsón, de esa forma ayudamos..." (Ana María, 52 años, ama de casa, Diácona de la iglesia, esposa del pastor).

"Y la doctora le dijo a Nadia (la hija del pastor) que calcula que la semana que viene ya va a dar a luz, pero ella está tranquila, porque está rodeada de hermanos, como vive en la Villa, en la parte de atrás del anexo, está rodeada de hermanos" (Ana María, 52 años, ama de casa, Diácona de la iglesia, esposa del pastor).

De este modo, la desigualdad en la apropiación que circulan por las redes pentecostales guarda relación con las distintas posiciones ocupadas en su estructura jerárquica. Ocupar las posiciones dominantes en la estructura religiosa le permitió al pastor y su esposa acceder a una vivienda para su hija en el terreno de una de las sedes de la iglesia. Como mencionamos, el capital social, en tanto fuente de poder, supone importantes inversiones materiales y simbólicas y de esfuerzos que implican otros gastos. Su utilidad se expresa en los beneficios materiales y simbólicos (el prestigio, por ejemplo) que permite apropiar y depende del lugar que se ocupa en la congregación.

Por otro lado -y como destacaron otras investigaciones empíricas-, las redes sociales pentecostales no producen la misma rentabilidad en todas las situaciones (Roberts 1968; Míguez 2001). En efecto, pertenecer a la red pentecostal es una estrategia de movilización social ascendente exitosa en casos de extrema pobreza, mas no sucede lo mismo cuando los agentes involucrados en la red han superado el escalón más bajo de la estructura social. En estas situaciones las demandas de inversión en tiempo y esfuerzo necesarias para el mantenimiento de las redes religiosas tienden a superar los beneficios (Míguez 2001). Esto se debe, en parte, a la pertenencia de clase social de los agentes involucrados. Las redes de las iglesias pentecostales entrelazan, en nuestro caso de estudio y en la mayoría de los casos, a pobres con pobres. Hecho que produce que los bienes y servicios intercambiables no proporcionan, en la mayoría de los

\footnotetext{
${ }^{11}$ En este sentido, es recurrente en el campo evangélico que a las iglesias se las identifique por el liderazgo que ejercen sus pastores. Así, algunos pastores han sido reconocidos por su injerencia en la esfera pública a nivel nacional e internacional, como es el caso de Luis Palau, Dante Gebel, Héctor Giménez, Claudio Freidzon, Salvador Delutri, Alfredo Smith entre otros.
} 
casos, soluciones a largo plazo. Las redes laborales entre iglesias pentecostales y familias miembros son menos frecuentes que las que unen a familias y a la congregación de los Hermanos Libres, objeto de análisis del siguiente apartado.

En síntesis, son diversas las prácticas que les permitieron a la iglesia de Malvinas Argentinas no sólo afianzarse en la localidad sino también expandirse. Dentro de estas estrategias destacamos la utilización de redes familiares preexistentes para abrir nuevas sedes. Una estructura flexible que posibilita la multiplicación de casas de oración y casas anexos, como así también la formación de nuevos líderes, hecho que ayuda a constituir al espacio religioso como lugar de crecimiento, pertenencia e identidad. A su vez, la preeminencia de prácticas no mediadas por la lecto-escritura que se amoldan más a las necesidades y nivel educativo de los fieles. Los puentes sustitutivos y asociativos entre las prácticas populares y el pentecostalismo constituyen otro de los factores que facilitan a esta forma de denominación crecer entre los sectores más pobres.

De lo expuesto hasta aquí emerge una imagen compleja del pentecostalismo como estrategia de reproducción social con una apuesta central en las redes de intercambio. Las iglesias pentecostales constituyen espacios donde tiene lugar un doble movimiento. Por un lado, el fortalecimiento de las redes de intercambio y, por el otro, la ampliación de dichas redes. Es decir, el vínculo religioso permite crear redes de reciprocidad caracterizadas por una intensa solidaridad entre los creyentes, sin excluir por ello la participación en otras redes sociales por fuera de la institución religiosa.

Sin embargo, ser parte de las redes pentecostales no produce los mismos beneficios en todas las situaciones. Las redes sociales pentecostales son agentes de movilidad social ascendente sólo en casos de extrema pobreza (Roberts 1968; Míguez 2001). Pero no sucede lo mismo cuando los agentes involucrados en la red han superado el escalón más bajo de la estructura social. En estas situaciones las demandas de inversión en tiempo y esfuerzo necesarias para el mantenimiento de las redes religiosas tienden a superar los beneficios (Míguez 2001). Esto se debe, en parte, como ya hemos analizado, a la pertenencia de clase social de los agentes involucrados. Las redes de las iglesias pentecostales entrelazan, en nuestro caso de estudio y en la mayoría de los casos, a pobres con pobres.

Otra de las variables de suma importancia para captar la desigual apropiación de recursos que circulan por las redes pentecostales implica entender a las instituciones como espacios de conflicto. Es decir, captar la dinámica interna del espacio de las congregaciones como lugar de juego, apuesta y lucha. Al interior de la institución religiosa los agentes están dotados de distintas especies de capital y de distintas trayectorias. Estas desigualdades ubican a los agentes en posiciones diferenciales, otorgando sólo a algunos el poder de la enunciación, de la toma de decisión, de la capacidad de gestión y manejo de determinados recursos.

\subsection{Tejiendo redes: la iglesia de los Hermanos Libres y familias pobres}

\subsubsection{Historia y prácticas institucionales}

El crecimiento y éxito de los pentecostales, en alguna medida, invisibilizó la presencia de otras minorías dentro de los grupos protestantes, entre ellas la agrupación de los Hermanos Libres.

Esta agrupación de origen inglés llega a Argentina en lo que se ha denominado "la era aluvial" en los años ochenta del siglo pasado. Este momento histórico coincidió con la expansión de la red ferroviaria inglesa y la llegada de funcionarios-misioneros de dicha denominación 
religiosa. Los Hermanos Libres atrajeron principalmente a elementos de la clase media, profesionales, dueños de fábricas o negocios y comerciantes. Este hecho, dejó su impronta en la conformación de un liderazgo que recayó habitualmente en personas de estratos medios (Roldán 1996). Así, estas iglesias se constituyeron según las normas y representaciones de clase media. El apoyo a las reglas de la democracia electoral, la valorización del saber intelectual para sus líderes y una planificación del culto hecha en función del concepto de orden (d'Epinay 1973) son algunas de las características de esta impronta de clase.

Desde su inserción en el país, los Hermanos Libres pusieron de manifiesto su sensibilidad hacia los necesitados y pobres. La asistencia a carencias fue casi una constante de misioneros y misioneras llegados al país (Roldan 1996). Las prácticas desplegadas por los recién llegados consistieron fundamentalmente en el reparto de folletos, reuniones "al aire libre", uso de carpas y el coche bíblico. Los Hermanos Libres utilizaron las líneas ferroviarias para radicar iglesias en las distintas ciudades, pudiéndose establecer como ejes los ramales centrales, especialmente Buenos Aires, Rosario y Córdoba (Roldán 1996).

Una iglesia-anexo de esta congregación se instala en la localidad de Malvinas Argentinas aproximadamente catorce años atrás. Luego de varios años de presencia en el barrio, la iglesiaanexo no logra consolidarse; si bien se aprecia un crecimiento de sus miembros éste no es significativo. En el año 2007 se produce una ruptura en la historia institucional con la llegada a la localidad de un nuevo pastor -con dedicación exclusiva a las actividades de la iglesia- y su familia, quienes se instalan en una vivienda a dos cuadras de la iglesia. A su vez, nuevos líderes, más jóvenes y "menos ortodoxos" de la iglesia central, según una de las mujeres entrevistadas, hacen su llegada de manera permanente a la institución.

Algunas de las estrategias desplegadas consistieron en una modificación del lenguaje religioso y un cambio en los temas de los mensajes de las reuniones generales y en las reuniones a cargo de los distintos ministerios.

-Y también vimos que eran personas que tienen muy bajo el nivel educativo, o sea, pensábamos cuántas palabras pueden tener. Porque nosotros veíamos que eran personas que no leían, entonces tenían un vocabulario muy básico, que palabras que te pueden parecer muy comunes que nunca habían escuchado (...) porque nos pasó también esos años donde había pocas concurrencias de personas la iglesia había caído en ese error, o sea llevaba la misma gente de la iglesia central de Córdoba, el mensaje era exactamente igual, la estructura de la reunión era exactamente igual, hoy nos damos cuenta que no, que, bueno, que había que llegar de otra forma, y bueno, más de treinta minutos no te podés exceder en un mensaje y te digo que es mucho... (Daniela, 35 años, ama de casa, profesora de educación física sin ejercer, Líder del Ministerio de Mujeres).

Es así que, como plantea Martínez (2009) siguiendo a Bourdieu, la unidad de la religión en sociedades complejas y divididas en clases, como la nuestra, no está dada por la unicidad del mensaje, sino por un trabajo religioso de unificación constante renovado que realizan los agentes autorizados, en el que los rituales, los símbolos, la disciplina, el reconocimiento de la autoridad, tienen tanta más importancia que la uniformidad de la creencia.

A su vez, los distintos mecanismos implementados por los líderes de la iglesia aseguran un conocimiento personalizado de las necesidades y de la situación de cada miembro. Con ello, la visita a los hogares constituye una práctica frecuente de los distintos líderes de la iglesia, principalmente del pastor. Tal práctica permite poco a poco ampliar el radio de la congregación 
en la localidad.

-¿Y cómo llegan a la iglesia?

-A la Iglesia, después que Marcelo (su marido) tuvo la segunda operación, que estaba deprimido, un día cayó Ezequiel (Pastor del anexo) acá. Un día le dice que va a venir... o sea íbamos a la casa de mi hermano siempre por cumpleaños, no sé de quién era el cumpleaños ese día, que dice Ezequiel "ya voy a ir a visitarlos, si no le molesta", "no" dice Marcelo. Y bueno, fue. Comenzaron a charlar, le trajo una Biblia y ahí se comprometió que íbamos a ir el domingo y comenzamos a ir. (...) De diciembre que estamos yendo (Laura, 46 años, ama de casa, miembro de la iglesia).

La formación de distintos ministerios constituyó otra de las prácticas desplegadas para incorporar nuevos fieles. De esta manera, los distintos ministerios de la iglesia (de mujeres, hombres, matrimonio, jóvenes, pre-adolescentes y la escuelita dominical) constituyen un espacio que agrupa a los fieles según la edad, el sexo, el estado civil, problemáticas e intereses. Estos espacios estructuran la experiencia de los fieles en base a enseñanzas, oraciones, lecturas bíblicas y charlas informales.

Así, por ejemplo, en las reuniones de mujeres el tema-eje está íntimamente relacionado con los problemas de la vida privada. En coincidencia con los planteos de Machado y Mariz (2005), podemos decir que, conjuntamente con el pentecostalismo y los grupos carismáticos católicos, en esta iglesia el énfasis en el universo familiar constituye el principal tema y atractivo para las mujeres. Los conflictos conyugales son, en vía de regla, traducidos en términos de comportamientos desviantes de los compañeros varones -infidelidad o vicios relativos a las drogas y a las diferentes formas de juego-, reservando para las mujeres los problemas relativos al temperamento y a las relaciones interpersonales. De modo que, cuando la mujer es responsabilizada por las desavenencias, lo es por su <<falta de paciencia $\rangle>$, <<agresividad $\rangle>0$ $<<$ egoísmos〉>, es decir, por la ausencia de aquellas características atribuidas a la naturaleza femenina en el sistema de género de inspiración patriarcal: $<<$ la abnegación $\rangle>, \quad<<$ la dedicación $>>$, <<la generosidad $>>,<<$ la docilidad $>>$ y la $<<$ resignación $>>$, entre otras (Machado y Mariz 2005).

-Entonces nos vimos en la necesidad de educarlo con cosas que a lo mejor para uno le son fáciles de entender, nos dimos cuenta que sus valores estaban desequilibrados... entonces tratamos con la palabra de Dios porque para todo es útil, la palabra de Dios tratarle de enseñar. En la reunión de mujeres enseñarles que el varón es el jefe de la casa, o sea el jefe, el sacerdote del hogar dice la Biblia que lo tenés que amar y respetar porque Dios te dice que tiene que ser así. Entonces vas marcando algunas pautas y valores que van cambiando y transformando su vida, los esposos ven que sus mujeres están de una manera diferente (Daniela, 35 años, ama de casa, profesora de educación física sin ejercer, Diácona del Ministerio de Mujeres).

-Tenemos que ser mujeres de decisión, tenemos que decidir hacerlo. Decidir hacer de nuestro esposo la relación primera, hacer de nuestro esposo nuestra relación numero uno. Fomentar la amistad con él, que él sea lo más importante. Yo sé que no es fácil. Muchas veces nosotras sobre invertimos en los hijos y sub invertimos en nuestro marido. Y eso no es lo correcto, entonces tenemos que empezar a escoger un tiempo para estar con él, un tiempo a solas (Carmen, 39 años, ama de casa, esposa del pastor, Líder del Ministerio de Mujeres). 
En estos testimonios se sostiene una perspectiva de género limitada y excluyente de derechos. Sin embargo, afirmar esto no implica negar, como sostiene Tarducci (1993), que aun cuando el pentecostalismo ( $\mathrm{u}$ otros grupos religiosos) legitima el poder y autoridad de los hombres por sobre las mujeres, las enseñanzas de la iglesia modifican aspectos de la conducta masculina que son perjudiciales para las mujeres y los niños, como la violencia doméstica, la ebriedad, y sirve para mejorar la posición económica de las mujeres convertidas. A su vez, el culto constituye, para la mayoría de las mujeres pobres, el único espacio extra-familiar al que tienen acceso y es a través de este espacio que logran, muchas veces, desarrollar capacidades de liderazgo -fundamentalmente dirigiendo diversos ministerios-.

Cabe agregar que, desde el prisma religioso de esta institución, las prácticas desviantes y pecaminosas -moralmente no aceptadas- son leídas, en parte, como la causante de los problemas económicos y sociales que vive la población de Malvinas Argentinas.

-Nosotros vemos que la gente de Malvinas se da mucho el abuso por el nivel social que hay también, viven todos encimados, viven en dos por dos mucha gente, se da mucho también que la mujer no viva con su propio marido, entonces las hijas no son de él y se produce el abuso porque son padres adoptivos mezclados con vicios, o sea... vemos muy fuerte en Malvinas mucha miseria, lo cual eso nosotros estamos orando mucho como iglesia, porque nosotros a todo lo vemos espiritualmente y creemos que hay un trasfondo espiritual en esto (Daniela, 35 años, ama de casa, profesora de educación física sin ejercer, Líder del Ministerio de Mujeres).

-A lo largo de la charla Ezequiel definió al barrio como "una babel de confusiones". Se declaró contento con su obra y con el recibimiento por parte de la gente de Malvinas. $\mathrm{Su}$ "misión es salvar a la gente del mal del pasado". Y agregó que él percibía mucha promiscuidad, sufrimiento y soledad en la gente (Ezequiel, 42 años, Pastor de la iglesia).

Como queda plasmado en estos relatos, desde la institución religiosa se reduce, de algún modo, la problemática de la pobreza a una cuestión moral y pecaminosa. Esta visión pietista cree que la solución de los problemas sociales depende de la conversión de los individuos, ignorando la complejidad de los asuntos involucrados, que va mucho más allá de las relaciones interpersonales. De este modo, el espacio religioso genera un sentido legitimizante de la relaciones de obediencias establecidas en una sociedad determinada que impide el cuestionamiento del status quo y la puesta en marcha de una estrategia colectiva para demandar determinados derechos. Como plantea Martínez siguiendo a Bourdieu, "la intervención más poderosa de los líderes religiosos reside en el efecto de imposición de la jerarquía misma, de un modo jerárquico de pensamiento que ordena el cielo tal como está ordenada la tierra, y así naturaliza, el orden social existente (Martínez, 2009:24).

\subsubsection{Don y contra don: redes laborales entre familias e iglesias}

Como adelantábamos en la introducción de este trabajo, dentro del conjunto de prácticas institucionales de las iglesias protestantes la construcción de redes sociales tiene un lugar destacado. Y la diferenciación de clases entre líderes y los fieles en la iglesia de los Hermanos Libres repercute en las características que adquieren las redes de intercambio. Los líderes de la 
congregación provienen de sectores de clase media universitaria (pertenencia de clase que continúa vigente desde la llegada de los primeros Hermanos Libres al país), mientras que los fieles son de clase baja con un nivel de escolaridad que llega sólo en algunos casos a secundario completo.

De esta manera, la diferenciación entre líderes y fieles es doble. Por un lado, hay una separación según la posición ocupada en el espacio social global, es decir, según la pertenencia de clase social. A su vez, la diferenciación producto de la división de trabajo de producción religioso (Maduro 1980) que divide a los agentes entre los especialistas que tienen "la competencia específica" y los "saberes secretos" para ejercer su función y por eso un capital religioso valorado y, por otro lado, los laicos que, al no poseer estas competencias, se encuentran en una posición de subordinación legitimando el ejercicio y la posición de los primeros (Bourdieu 2009).

Sin embargo, esta diferenciación de clase entre líderes y fieles posibilita la existencia de redes de intercambio más capitalizadas que las que tienen lugar en la iglesia pentecostal. Como plantea Baranger (2004), el capital social en la perspectiva de Bourdieu es relacional por partida doble, al basarse en relaciones sociales entre actores que interactúan y ocupan una posición dentro del espacio social. El espacio religioso permite la interacción de agentes de distintas clases sociales, frente a una sociedad que se caracteriza cada vez más por fragmentos aislados. ${ }^{12}$

De esta forma, las redes sociales al interior de la iglesia unen a pobres con no-pobres, posibilitando en muchas ocasiones solucionar el problema del desempleo. Cabe aclarar que, si bien estas redes no solucionan el problema de la pobreza estructural, si les proveen a los sujetos con bajo nivel de escolaridad formal un trabajo estable que les permite planificarse a más largo plazo y paliar la situación.

-(...) en un tiempo necesitaba trabajo y por medio de los líderes conseguí trabajo en una fábrica. Y después, si necesitaba, por ahí vinieron y me ofrecieron ropa, si necesitaba para mi hijo, para mí, siempre con algo para darme, ofrecerme o preguntándome si necesitaba algo, siempre (Daniela, 35 años, ama de casa, profesora de educación física sin ejercer, Líder del Ministerio de Mujeres).

El caso de Laura representa un ejemplo de las múltiples personas que consiguieron trabajo en fábricas o como empleadas domésticas por medio de las redes laborales de la iglesia. Así, las redes sociales enlazan las prácticas de pobres con no-pobres y permiten a los primeros obtener, por ejemplo, un trabajo estable que posibilita estructurar de una manera diferente sus estrategias

\footnotetext{
${ }^{12}$ Son numerosos los autores (Prévôt Schapira, 2001; Tirmanti, 2004) que utilizan el concepto de fragmentación para dar cuenta de los cambios recientes en las ciudades latinoamericanas. La sociedad contemporánea se compone cada vez más de fragmentos, de islas, de universos auto-referenciales que tienden a contener su propia lógica de acción y representación, sus universos simbólicos-culturales, sus específicos espacios de sociabilidad. Se produce así un fuerte proceso de segregación social donde la tendencia es generar espacios socioculturalmente homogéneos que disminuye drásticamente las oportunidades de contactos e interacciones informales entre los pobres y las otras clases sociales, y con ello se reduce asimismo el capital social que les proveía de una diversidad de recursos. En este sentido, la separación física los limita y provoca la pérdida de su capital social (Kaztman, 2001; Santillán, 2007) y específicamente, de las redes laborales. En definitiva, el tema de la segregación residencial adquiere una relevancia mayor en la medida en que las estrategias de localización de las diferentes clases sociales, el decaimiento de los espacios públicos y la fragmentación urbana influyen negativamente sobre la "integración social en la ciudad" (Capdevielle, et al., 2013).
} 
de reproducción social. El capital social colectivo de estas redes puede reconvertirse en conocimiento (capital cultural) o en un ingreso regular relativamente estable (las "referencias" constituyen capital social objetivado de uso individual, susceptible de ser reconvertido en capital económico bajo la forma de "trabajo").

En síntesis, dentro de estas estrategias de esta iglesia destacamos un constante proceso de adaptación a las necesidades de los fieles. La reestructuración de las reuniones, de los temas abordados y del lenguaje utilizado en las mismas fue parte de la búsqueda institucional por llegar a la población de Malvinas. Estos cambios fueron acompañados de un conocimiento personalizado de las necesidades de cada fiel por medio de la oración y la visita a los hogares. La construcción de redes laborales para hacer frente al problema del desempleo en una población con bajo nivel de escolaridad formal es otra de las prácticas frecuentes que entrelaza la vida de las familias con la iglesia. De este modo, el capital social que provee pertenecer a la iglesia de los Hermanos Libres posee un mayor grado de rentabilidad que el que provee la iglesia pentecostal. Sin embargo, este capital posee, a nuestro entender, el límite que provee la visión institucional de la iglesia frente a la problemática de la pobreza. Reducir este fenómeno social a una cuestión moral naturaliza y, en alguna medida, justifica la existencia de la misma, olvidando la génesis social de su producción. Este hecho impide el cuestionamiento al status quo y, con ello, la puesta en marcha de una estrategia colectiva para demandar determinados derechos.

\section{4. ( $\operatorname{Re})$ pensando una vez más el concepto de capital social.}

El concepto de capital social cobró fuerzas en las ciencias latinoamericanas en los años noventa por la influencia de organismos internacionales como el Banco Mundial y el Banco interamericano de Desarrollo. Desde el paradigma sostenido por estos organismos, el concepto de capital social se volvía fructífero en tanto que el mismo iluminaba las posibilidades de una sociedad auto-organizada y autorregulada para resolver las fallas del mercado sin necesidad de una intervención estatal (Hintze, 2004). En esta misma línea, en el año 2000, la Comisión Económica de las Naciones Unidas para América Latina (CEPAL) y la Universidad del Estado de Michigan de Estados Unidos organizaron una Conferencia titulada <<En busca de un nuevo paradigma: capital social y reducción de la pobreza en América Latina y el Caribe >. En ella se buscó examinar las aplicaciones del capital social en la reducción de la pobreza como un intento de "empoderar" a los sectores más pobres. Así, el impulso de este concepto se debió a que el mismo concentró la atención en las consecuencias positivas de la sociabilidad a la vez que dejó de lado sus rasgos menos atractivos. Desde esta perspectiva del capital social las relaciones de poder quedan excluidas como elemento explicativo de las prácticas sociales. Es decir, encorsetadas en una mirada de la realidad social que se centra en el orden y en el funcionamiento armonioso de los individuos y de los colectivos, están totalmente ausentes herramientas analíticas capaces de dar cuenta de las fuentes de poder y de conflicto, es decir, de las diferencias sociales, del diferente posicionamiento que pueden tener -y tienen- los agentes sociales (Gutiérrez, 2008)

En contraposición, la noción de capital social que utilizamos se sustentó en la perspectiva teórica bourdieusiana. Matriz teórica que nos permitió contemplar las relaciones de poder y conflicto al interior de los espacios religiosos. De este modo, hemos mostrado en las redes religiosas de la iglesia de los Hermanos Libres, que unen pobres con no pobres, provee a los agentes soluciones a largo plazo, insertándolos en el mercado laboral. Sin embargo, como analizamos, estos intercambios desiguales entre líderes y fieles instituyen relaciones de dominación simbólica basadas en la interacción entre agentes ubicados en distintas posiciones y 
relaciones. El poder no sólo circula con los recursos sino que se reactualiza en cada intercambio, otorgando a quien los lleva a cabo un capital de reconocimiento. Ahora bien, las redes religiosas pentecostales, que entrelazan a pobres con pobres, circulan una diversidad de bienes y servicios encaminados a dar respuesta a necesidad del presente inmediato, a los imponderables de la vida cotidiana. Como sostiene Bourdieu el capital social es un multiplicador de otros capitales pero es difícil multiplicar cuando los recursos son pocos o escasos. El capital social religioso de las familias pobres constituye una respuesta de alcance limitado para aportar a la reproducción de los sectores pobres. Nuestra investigación nos permite concluir junto a los planteos de Hintze (2004) que el énfasis por potenciar el capital social que los organismos internacionales han analizado durante tres décadas, tiende a eludir el problema central de "los pobres": que el núcleo duro de la superación de la desigualdad y la pobreza pasa centralmente por la disminución del desempleo, la precarización laboral y por una verdadera redistribución de la riqueza.

\section{Bibliografía}

Adamovsky, Ezequiel. 2012. Historia de las clases populares en la Argentina: Desde 1880 hasta 2003. Buenos Aires: Sudamericana.

Algranti, Joaquín. 2009. Neo-pentecostalismo y protesta social. Estudio de la comunidad evangélica Rey de Reyes. Tesis de doctorado, Buenos Aires: Universidad de Buenos Aires, Facultad de Ciencias Sociales.

Aviles David, Capdevielle, Julieta y Micheli, Alavaro. 2012. “El modelo 'pastorcéntrico': Análisis de las relaciones de poder en tres iglesias de la provincia de Córdoba". VII Jornadas Internacionales 'Ciencias Sociales y Religión' Modernidad, secularización y religiones en Argentina, noviembre. Buenos Aires - Argentina.

Baranger, Denis. 2004. Epistemología y metodología en la obra de Pierre Bourdieu. Buenos Aires: Prometeo libros.

Bartolomé, Leopoldo. 1985. "Estrategias adaptativas de los pobre urbanos: el efecto 'entropico' de la relocalización compulsiva”. Relocalizados: Antropología Social de las Poblaciones Desplazadas. Bartolomé, Leopoldo (Compilado), Buenos Aires: Ediciones, IDES, 67-115.

Bianchi, Susana. 2004. Historia de las religiones en la Argentina. Las minorías religiosas. Buenos Aires: Ed. Sudamericana.

Beccarria, Luís y López, Néstor. 1996. "Notas sobre el comportamiento del mercado de trabajo urbano" Sin trabajo. Las características del desempleo y sus efectos en la sociedad argentina. Becarria, Luis y López, Néstor. (compiladores). Buenos Aires: UNICEF-Losada. 17- 46.

Berges, Juana. 2008. "Entre la ortodoxia y los cambios. Un análisis del pentecostalismo en Cuba". América Latina y el Caribe: territorios religiosos y desafíos para el diálogo. Alonso, Aurelio. (Compilador) Buenos Aires: CLACSO, 201-228.

Bourdieu, Pierre. 2009. "Génesis y Estructura del Campo Religioso". La eficacia simbólica. Religión y política. Bourdieu, Pierre. Buenos Aires: Editorial Biblos. 41-89. . 2000. La distinción. Criterios y bases sociales del gusto. Madrid: Taurus. .1980. "Le capital social. Notes provisoires". Revista Actes de la Recherche en Sciences Sociales, $\mathrm{n}^{\mathrm{o}}$ 31: 2-3.

Campos Machado, Maria das Dores y Mariz, Cecília. 2005. "Mujeres en tres grupos religioso en Brasil: una comparación entre pentecostales y católicas." Revista Religión y Género. 
Enciclopedia Iberoamericana de Religiones. Madrid: Editorial Trotta: 203-231.

Capdevielle, Julieta; Ceconato, Diego y Madrini, María. 2013. "Segregación urbana y mercantilización del territorio en la ciudad de Córdoba, Argentina: el caso de villa la maternidad". Revista Iberoamericana de Urbanismo. Barcelona -Buenos Aires -Palma de Mallorca. Volumen 9.

Chavez Molina, Eduardo y Raffo, María Laura. 2005. "Ferias y feriantes. Lógicas de reproducción y trayectorias laborales". Los nuevos rostros de la marginalidad. La superviviencia de los desplazados. Mallimaci, Fortunato y Salvia, Agustín. (Comp.) Buenos Aires: Biblos - Instituto Gino Germani. 57-74.

Covarrubias Cuéllar, Karla. 2010. "La historia oral en la reconstrucción del sentido de vida de cinco familias pobres y evangélicas. Un enfoque generacional". Revista Question, vol. 1, No 28. ISSN 1669- 6581.

- (1998) "Etnografía: el registro del mundo social desde la vida cotidiana (apuntes metodológicos)" Revista Estudios sobre las Culturas Contemporáneas, Diciembre, año/vol. IV, Universidad de Colima, Colima, México número 8: 93-119.

D’Epinay, Christian Lalive. 1973. Religión e Ideología en una perspectiva sociológica. Puerto Rico: Centro de Estudios Cristianos.

Forni, Floreal; Mallimaci, Fortunato; Cardenas, Luis (Coordinadores) .2003. Guía de la diversidad religiosa. Buenos Aires: Editorial Biblos.

Grassi, Estela. 1997. La política social del neoliberalismo. Supuestos que orientan la acción y problemas pendientes. Buenos Aires: Mímeo.

Gutiérrez, Alicia. 2004. Pobre', como siempre... Estrategias de reproducción social en la pobreza. Córdoba: Ferreyra Editor.

. (2008), "El capital social" en la pobreza: apuesta, medio y resultado de luchas simbólicas". Estudios sobre pobreza en Argentina. Aproximaciones teórico metodológicas. Pavcovich, Paula y Truccone, Damián. Córdoba: Editorial Universitaria Villa María, Universidad Nacional de Villa Maria. 29- 48.

Hintze, Susana. 2004. "Capital social y estrategias de supervivencia. Reflexiones sobre el 'capital social de los pobres"”. Política social y economía social. Debates fundamentales. Danani, Claudia. (Comp.). Buenos Aires: Altamira- Fundación OSDE-UNGS. 143-166.

JELIN, Elizabeth., LLOVET, Juan y RAMOS, Silvia. 1999. "Un estilo de trabajo: la investigación microsocial", Historias y relatos de vida: investigación y práctica en las ciencias sociales. Benoga, José. (comp.) Santiago de Chile: Ediciones Sur. 130-146.

Kaztman, Rubén. 2001. "Seducidos y abandonados: el aislamiento social de los pobres urbanos". Revista CEPAL, Santiago de Chile. № 75.

Lomnitz, Larissa. 1978. Como sobreviven los marginados. México: Siglo XXI.

Maduro, Otto. 1980. Religión y conflicto social. México: Centro de Estudios Ecuménicos.

Mallimaci, Fortunato y Giménez- Béliveau, Veronica. 2006. "Historia de vida y métodos biográficos". Estrategias de Investigación cualitativa. Vasilachis De Gialdino, Irene. (Coord) Barcelona: Gedisa. 175-212.

Mariz, Cecília Loreto. 1994. Coping with Poverty in Brazil. Temple University Press, Philadelpia. 1990. Igrejas pentecostais e estrategias de sobrevivencia. En Religiåo e Cidadania, editado por J. Braga, pp. 89-112. DEA-UFBA-EGBA, Bahia.

Martinez, Ana Teresa. 2009 "Introducción. Religión y creencias en el trabajo sociológico de Pierre Bourdieu”. La eficacia simbólica. Religión y política. Bourdieu, Pierre. Buenos Aires, Editorial Biblos. 9-40. 
Míguez, Daniel. 2001. "La conversión religiosa como estrategia de supervivencia: Los pentecostales y el descenso social durante la "década perdida". Revista Intersecciones Antropol., ene./dic. 2001, no.2: 73-89.

Minujin, Alberto et al. (1993), Cuesta Abajo. Los nuevos pobres: efectos de la crisis en la sociedad argentina, Buenos Aires, UNICEF-Losada.

Neiman, Guillermo y Quaranta, Germán. 2007. "Los estudios de caso en la investigación sociológica". Estrategias de investigación cualitativa. Vasilachis De Gialdino, Irene. (Coord.) Buenos Aires: Gedisea editorial. 213- 237.

Prévôt Schapira, Maria. 2001. "Fragmentación espacial y social: conceptos y realidades". Revista Perfiles Latinoamericanos, diciembre, número 019. Facultad Latinoamericana de Ciencias Sociales, Distrito Federal México.33-56.

Ramos, Silvia. 1981. Las relaciones de parentesco y ayuda mutua en los sectores pobres urbanos: un estudio de caso. Buenos Aires: CEDES.

Reguillo Cruz, Rossana. 1996. La construcción simbólica de la ciudad. Sociedad, desastre y comunicación. México: Editorial Pandora.

Roldan, Alberto Fernando. 1996. "Comprensión de la realidad social en el discurso teológico del los Hermanos Libres en la Argentina (1882- 1955)". En Cuaderno de Teología. Vol. XV, N 1 2. 23-53.

Roberts, Brian. 1968. "Protestant groups and coping with urban life in Guatemala city". Revista American Journal of Sociology, 73: 753-767.

Salvia, Agustín. 2002. "Fragmentación social y heterogeneidad laboral". Revista Lavboratorio, 9, Instituto de Investigaciones Gino Germani, Universidad de Buenos Aires.

Santillan, Maria. 2007. "La ciudad de Córdoba y la localización de los movimientos sociales en lucha”. XXVI Congreso ALAS, Guadalajara, México, Agosto.

Semán, Pablo. 2000. "El Pentecostalismo y la religiosidad de los sectores populares" Desde Abajo: la transformación de las identidades sociales. Svampa, Maristella, (Comp.), Buenos Aires: Universidad Nacional de General Sarmiento-Editorial Biblos. 155-180.

. 2006. "El pentecostalismo y el rock chabón en la transformación de la cultura popular" Entre santos, cumbias y piquetes. Las culturas populares en la Argentina reciente. Míguez Daniel y Semán Pablo (editores). Buenos Aires: Biblios. 197-218.

. 2010. "De a poco mucho: las pequeñas iglesias pentecostales y el crecimiento pentecostal. Conclusiones de un estudio de caso". Revista Cultura y Religión; Año: 2010 vol. 4: $16-33$.

Svampa, Maristella. 2005. La sociedad excluyente. La Argentina bajo el signo del neoliberalismo. Buenos Aires: Taurus.

Tarducci, Mónica. 1993. "Pentecostalismo y relaciones de género: una revisión" Nuevos movimientos religiosos y ciencias sociales (I), Frigerio, Alejandro (editor). Buenos Aires: Centro editor de América Latina S.A. 81-96.

Tecco, Claudio y Bressan, Juan Carlos. 2002- 2003. “Área Metropolitana Córdoba: análisis de asentamientos y de sus articulaciones al sistema urbano metropolitano. Los casos Estación General Paz y Malvinas Argentinas”, Informe de investigación: Mímeo.

Tiramonti, Guillermina. 2004. "La fragmentación educativa y los cambios en los factores de estratificación" La trama de la desigualdad educativa. Mutaciones recientes en la escuela media. Tiramonti, Guillermina (Comp.) Buenos Aires: Ed. Manantial. 15- 45.

Torrado, Susana. 1982. El enfoque de las estrategias familiares de vida en América Latina: Orientaciones teórico-metodológicas, Cuadernos del CEUR, núm. 2, Buenos Aires. 


\section{Fuentes estadísticas:}

CEIL PIETTE CONICET "Primera Encuesta sobre Creencias y Actitudes Religiosas en Argentina". En 〈http://www.ceil-piette.gov.ar/areasinv/religion/relproy/1encrel.pdf > acceso 2 de junio de 2010 .

-Relevamiento de las condiciones objetivas de vida de la población de la tercera sección de Malvinas en el marco del proyecto de investigación: "Redes y capitales en las estrategias de reproducción social de familias pobres" (SECYT-UNC: Res. 12254/6-CONICET) dirigido por Alicia B. Gutiérrez. 